\title{
Modulation of Peptide Release from Single Identified Aplysia Neurons in Culture
}

\author{
Matthew D. Whim and Philip E. Lloyd \\ Department of Pharmacological and Physiological Sciences, University of Chicago, Chicago, Illinois 60637
}

\begin{abstract}
Aplysia neurons $B 1$ and $B 2$ contain large amounts of the neuropeptides $\mathrm{SCP}_{\mathrm{A}}$ and $\mathrm{SCP}_{\mathrm{B}}$. When grown in culture, individual B1 and B2 cells incorporate ${ }^{35} \mathrm{~S}-m e t h i o n i n e$ into the SCPs, which can be released in a stimulus- and calciumdependent fashion (Lloyd et al., 1986). We now show that single cells can be stimulated in a manner to evoke release of the SCPs that declines only slightly with repeated stimulation. This has allowed us to examine the ability of several physiologically relevant agonists to modulate the stimulusevoked release of the SCPs. Bath application of either FMRFamide or 5-HT resulted in a significant decrease in the amount of SCPs released by intracellular stimulation of B1 or B2. The action of 5-HT was dose dependent with an inhibition of release of $\sim 70 \%$ at a concentration of $100 \mu \mathrm{M}$. $S_{C P}$ did not significantly affect release. The bath application of several compounds that are expected to elevate intracellular levels of CAMP were also found to depress release. To investigate the possibility that the agonists inhibited the release of the SCPs via a hyperpolarization of membrane potential (and perhaps a loss of spikes in the neurites), we examined the actions of 5-HT, FMRFamide, and SCP $\mathrm{A}_{\mathrm{A}}$ on several electrophysiological parameters intended to monitor the level of cell excitability. Surprisingly, even though 5-HT depressed the release of the SCPs from both cells, it depolarized and increased the excitability of B1, and hyperpolarized and decreased the excitability of B2. Furthermore, in contrast to the effects seen in culture, 5-HT depolarized both $\mathrm{B} 1$ and $\mathrm{B2}$ in situ. Thus, an agonist can depolarize and increase the excitability of a neuron while simultaneously inhibiting transmitter release from that neuron.
\end{abstract}

An understanding of the regulation of neurotransmitter release is one of the central questions in cellular neurobiology. One of the most studied preparations in this field has been the vertebrate neuromuscular junction where the release of $\mathrm{ACh}$ via stimulation of the presynaptic nerve produces discrete postsynaptic electrical events that can be recorded intracellularly in the muscle fibers. By recording these electrical events, many of the factors that regulate $\mathrm{ACh}$ release have been elucidated (e.g., see

Received Dec. 11, 1991; revised Mar. 20, 1992; accepted Apr. 3, 1992.

We thank P. J. Church, W. L. Pearson, G. A. Phares, and K. P. Scholz for critical reading of the manuscript. This work was supported by NINCDS Grant NS 23596 and by a Brain Research Foundation grant.

Correspondence should be addressed to Dr. Philip E. Lloyd, Department of Pharmacological and Physiological Sciences, University of Chicago, 947 East 58 th Street, Chicago, IL 60637.

Copyright (C) 1992 Society for Neuroscience $0270-6474 / 92 / 123545-09 \$ 05.00 / 0$
Rahamimoff and Katz, 1986). Over the last few years, it has become clear that many nerve cells contain multiple transmittcrs, commonly peptide cotransmitters in addition to a conventional transmitter. Although it has sometimes proven possible to measure the release of a peptide via its postsynaptic actions (Jan and Jan, 1983; Willard, 1990; Peng and Horn, 1991), it is often the case that neuropeptides do not directly gate ion channels, and consequently many studies have quantified peptide release by direct measurement of the released material (Holz et al., 1988; Walker et al., 1988). Such studies have led to a general picture of peptide release that differs significantly from the release of classical transmitters. Most strikingly, peptide release often requires bursts of high-frequency stimulation (Dutton and Dyball, 1979; Cazalis et al., 1985; Whim and Lloyd, 1989, 1990; Cropper et al., 1990; Willard, 1990), and in some cases it is likely that it is the frequency rather than the bursting pattern that regulates peptide release (Peng and Horn, 1991). Nevertheless, exceptions do occur and it should be noted that lowfrequency stimulation has becn shown to evoke peptide release from cultured Aplysia neurons (Lloyd et al., 1986), indicating that the mechanisms regulating release may differ among cells.

The small cardioactive peptides (SCPs) are two peptides found in Aplysia that have been demonstrated to be modulatory neurotransmitters. They are synthesized by individual neurons, and are localized to dense-core vesicles in central neurons and varicosities in the CNS, muscle, and gut (Lloyd et al., 1984, 1987; Mahon et al., 1985; Cropper et al., 1987). They have been shown to be released from the terminals of B15, a cholinergic motor neuron, and to modulate muscle contractions heterosynaptically primarily via a postsynaptic locus (Lloyd et al., 1984; Whim and Lloyd, 1989, 1990; Cropper et al., 1990). Identified buccal neurons B1 and B2 when grown individually in culture incorporate ${ }^{3} S$-methionine into the SCPS. Using intracellular stimulation and a combination of HPLC and liquid scintillation counting, it has been demonstrated that the ncwly synthesized SCPs are released in a stimulus- and $\mathrm{Ca}^{2+}$-dependent manner (Lloyd et al., 1986). In the present report, we make use of this approach to study further the release of the SCPs from neurons $\mathrm{B} 1$ and $\mathrm{B} 2$. As a technique for monitoring peptide release, this procedure offers several distinct advantages. First, the neurons are grown in isolation, thereby removing extrinsic sources of modulation. Second, it allows the application of putative modulators directly to the neuron of interest, thus avoiding the possibility of agonists acting secondarily via release of compounds from other cells. Third, the lack of other neurons and virtual absence of non-neuronal cells are likely to reduce proteolysis of released peptides.

We were primarily interested in the possibility that physio- 

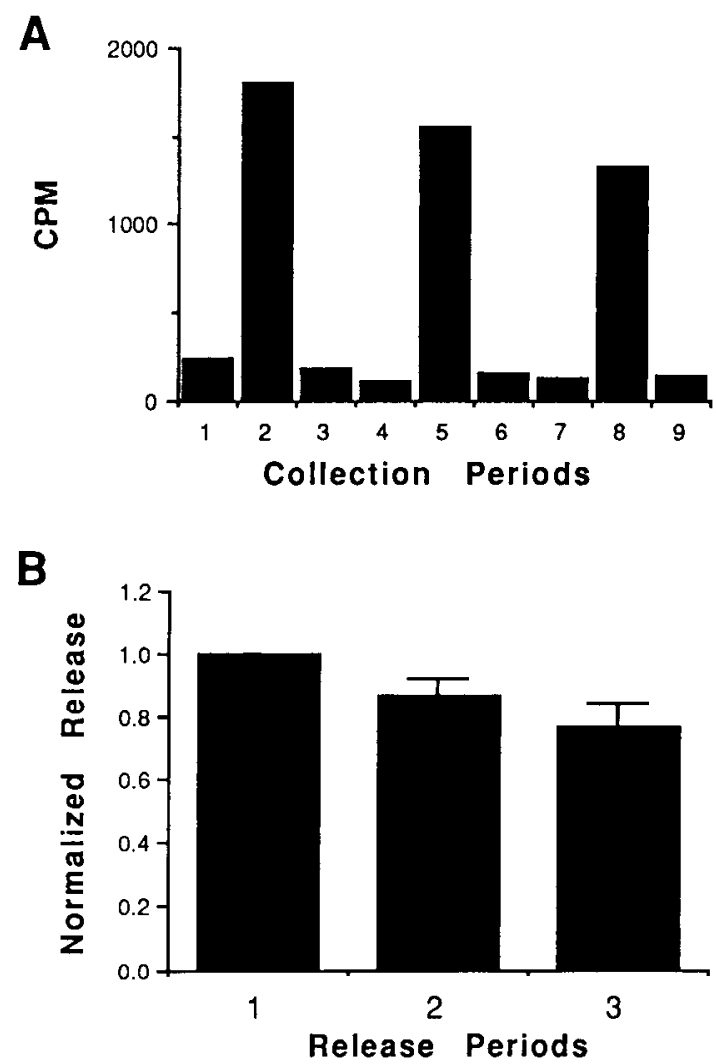

Figure 1. Reproducible release of labeled SCPs from cultured B1 and $\mathrm{B} 2$ cells. $A$, Results from an experiment in which a radiolabeled $\mathrm{B} 1$ cell was stimulated to fire three spikes in $0.5 \mathrm{sec}$ every other $0.5 \mathrm{sec}$ for 2 min followed by a $13 \mathrm{~min}$ period of silence (collection periods 2,5 , and 8 ). In the interstimulus collection periods, the cell was held hyperpolarized (see Materials and Methods). The released SCPs were determined using HPLC and liquid scintillation counting. $B$, Pooled data from four experiments as in $A$. The stimulation-dependent release of peptide was determined as the amount of radioactivity in the SCP fractions in the release period minus the mean of the corresponding fractions in the preand poststimulation wash periods. Release was then normalized to the first stimulation period. Background release was $11 \pm 5 \%$ (mean $\pm \mathrm{SD}$ ) of the initial stimulus-evoked release. Note that release periods 1,2 , and 3 correspond to experimental collection periods 2,5 , and 8 , respectively (see Materials and Methods). Values are mean \pm SEM $(n=4)$

logically relevant agonists might modulate $\mathrm{SCP}$ release. We concentrated on three compounds (SCP, FMR Famide, and 5-HT). Because these agonists were found to affect release differentially (see below), we also examined their actions on several electrophysiological parameters that would be expected to reflect the overall level of cell excitability. The agonists were chosen for several reasons. $\mathrm{SCP}_{A}$ (which is equipotent with $\mathrm{SCP}_{B}$ in all preparations examined; Lloyd et al., 1985) was used to determine if release was modulated by autoreceptors. 5-HT was examined because both $\mathrm{B} 1$ and $\mathrm{B} 2$ are known to receive innervation from a serotonergic neuron, the metacerebral cell (Weinreich et al., 1973; Gerschenfeld and Paupardin-Tritsch, 1974), stimulation of which has been shown to evoke postsynaptic potentials in both cells. 5-HT is also known to modulate an inward rectifier in $\mathrm{Bl}$ and $\mathrm{B} 2$ in culture (Lotshaw and Levitan, 1987). Finally, FMRFamide was tested since it is an agonist that frequently has opposing actions to 5-HT and the SCPs (Klein and Kandel, 1980; Abrams et al., 1984; Belardetti et al., 1987; Brezina et al., 1987) and because B1 and B2 appear to be postsynaptic to FMRFamide-immunoreactive varicosities (Lloyd et al., 1987). We show that repeated stimulation of B1 or $\mathrm{B} 2$ results in a reproducible release of the SCPs into the superfusate. Applications of the modulators FMRFamide and 5 -HT both result in a reversible decrease in peptide release, while $\mathrm{SCP}_{\mathrm{A}}$ is without significant effect. A variety of compounds, all of which are expected to raise intracellular CAMP levels, also depress release, thus suggesting that the actions of 5-HT, which have been shown to involve perturbations in the levels of CAMP in other systems in Aplysia, might be mediated via this second messenger system. Finally, although 5-HT depolarized B1 and B2 in situ, it had different effects on the two cells in vitro. That is, even though 5-HT was found to inhibit SCP release from both cells, it depolarized B1 and hyperpolarized B2 in culture, thus demonstrating that changes in transmitter release are not necessarily correlated with changes in a neuron's activity state.

\section{Materials and Methods}

Cell culture. Buccal ganglion cells B1 and B2 were isolated and cultured using techniques previously described (Schacher and Proshansky, 1983) with some minor changes (Hall and Lloyd, 1991). Briefly, buccal ganglia from Aplysia californica (30-80 gm) were desheathed and incubated in a $1 \%$ protease solution (Sigma type IX) in sterile normal artificial seawater (snASW) at $34^{\circ} \mathrm{C}$. Following the incubation, ganglia were washed with snASW. Neurons B1 and B2 were removed and plated individually in $1.5 \mathrm{ml}$ wells (Nunc multidishes) in $500 \mu \mathrm{l}$ of culture medium [50\% snASW: $50 \%$ Aplysia hemolymph, containing penicillin/streptomycin/ fungizone (GIBCO) to a final concentration of $1 \%$ ]. Following $36 \mathrm{hr}$ in culture, newly synthesized peptides were labeled by the addition of ${ }^{35} \mathrm{~S}-$ methionine (specific activity, $0.25 \mathrm{mCi} / \mathrm{ml}$ ) for $24 \mathrm{hr}$, and then washed with a high-Mg $\mathrm{Mg}^{2+}(110 \mathrm{~mm})$, low-Ca ${ }^{2+}(2 \mathrm{~mm})$ ASW for 6-12 hr.

Release of radiolabeled SCPS. Cells were impaled with two low-resistance microelectrodes: one to inject current, the other to monitor membrane potential. Both electrodes were of low resistance (2-4 M $\Omega$ ) since higher-resistance electrodes tended to drift over the long time course of the experiments. Controls indicated that these electrodes did not damage the cells (as monitored by the change in $R_{\text {input }}$ after impalement with the second electrode). The culture well was superfused

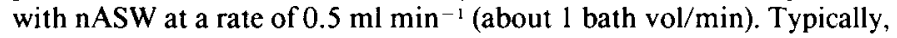
cells were spontaneously active $(1-3 \mathrm{~Hz})$ and were hyperpolarized to just below threshold. During the remainder of the experiment the membrane potential was monitored and held constant at this initial value. The superfusate contained $1 \mathrm{~mm}$ mercaptoethanol (to reduce oxidation of $\left.\mathrm{SCP}_{\mathrm{B}}\right)$ and $1 \mu \mathrm{M}\left[\mathrm{Tyr}^{8}\right]$-substance $\mathrm{P}$, an effective carrier peptide for the SCPs (Whim and Lloyd, 1989). Control experiments indicated that $1 \mathrm{~mm}$ mercaptoethanol did not significantly affect membrane potential, agonist actions, or the input resistance of the cultured cells (in agreement with a report that mercaptoethanol concentrations as high as $3 \mathrm{~mm}$ do not affect neuromuscular transmission in Aplysia; Lloyd ct al., 1986). Experiments consisted of nine sequential periods (six washes and three stimulations) each lasting $15 \mathrm{~min}$. Collection periods $1,3,4,6,7$, and 9 were washes. In periods 2,5 , and 8 , the cell was stimulated to fire three spikes in $0.5 \mathrm{sec}$ every other $0.5 \mathrm{sec}$ for $2 \mathrm{~min}$ (a total of 360 spikes) followed by a $13 \mathrm{~min}$ period of silence. Individual spikes were driven with $40 \mathrm{msec}$ depolarizing pulses. Superfusate from each collection period was maintained on ice, acidified with trifluoroacetic acid (TFA; final concentration, $10 \mathrm{~mm}$ ) spiked with $2 \mathrm{nmol}$ each of unlabeled $\mathrm{SCP}_{\mathrm{A}}$ and $\mathrm{SCP}_{\mathrm{B}}$, and then immediately passed through a $\mathrm{C}_{18}$ Sep-pak (Waters). Retained material was eluted with $2 \mathrm{ml}$ of $90 \% \mathrm{CH}_{3} \mathrm{CN}$ containing $10 \mathrm{~mm}$ TFA, lyophilized, and run on HPLC using a $\mathrm{CH}_{3} \mathrm{CN}$ gradient with TFA as a counterion (Hall and Lloyd, 1991). Fractions coeluting with unlabeled synthetic SCPs were collected and counted using a liquid scintillation counter. Experiments were only accepted if the cells remained healthy throughout the experiment (as judged by spike amplitude and shape).

For each experiment, the stimulation-dependent release of peptide was measured as the counts coeluting with unlabeled synthetic SCPs in the stimulation period, minus the mean of the equivalent fractions in the wash periods before and after that stimulation period. Background release was $14.6 \pm 8.3 \%$ (mean $\pm \mathrm{SD} ; n=39$ ) of the release observed in the first stimulation period. For the purposes of statistical analysis, 
the effect of a compound on SCP release was then compared to the release observed in the corresponding period of the control experiments (see Fig. 1) using a one-tailed $t$ test with a minimal level of significance of $P-0.05$. This procedure compensates for the slight decline in release that was observed with repeated periods of stimulation.

Because the carrier peptide was present throughout the experiments, we investigated whether it had any effect on SCP release. In four experiments, we introduced a $10 \mathrm{~min}$ pulse of $1 \mu \mathrm{M}\left[\mathrm{Tyr}^{8}\right]$-substance $\mathrm{P}$ into the superfusate just prior to the second stimulation period. Released SCPs were protected in these experiments by the presence of bovine serum albumin $(14 \mu \mathrm{g} / \mathrm{ml})$ in the superfusate. No effect of $\left[\mathrm{Tyr}^{8}\right]$-substance $P$ on release was found $(t=0.09$, not significant; $n=4)$. Finally, since all the agonists we used similarly affected the release of the SCPs from B1 and B2, the data were pooled for both neurons. However, since serotonin was found to depolarize B1 but to hyperpolarize B2, in the examination of cell excitability by serotonin we differentiate between the cells (see below).

Several compounds were maintained as stock solutions and diluted into ASW prior to each experiment: serotonin (in $10 \mathrm{~mm}$ acetic acid; final concentration of vehicle in the bath was $10^{-5} \mathrm{M}$ ), forskolin (FSK) and 1,9-dideoxy-forskolin (Di FSK; in ethanol, final concentration, $0.04 \%$ ), and a modified form of forskolin, 7-deacetyl-6-[ $N$-acetylglycyl]forskolin (Mod FSK; in dimethyl sulfoxide; final concentration, $0.25 \%$ ). In experiments using these compounds, the superfusates for all the collection periods contained the vehicle. All chemicals were obtained from Sigma, except for the peptides (American Peptide Co.) and the modified forskolin (Calbiochem).

Measurements of input resistance and cell excitability. Membrane potential was held constant at $-40 \mathrm{mV}$ throughout these experiments by manually adjusting the DC current. Input resistance was monitored using $0.5 \mathrm{nA}$ hyperpolarizing pulses $0.5-2 \mathrm{sec}$ in duration. Cell excitability was measured as the response of the cell to $1.5 \mathrm{nA}$ step depolarizations $2 \mathrm{sec}$ in duration. When the actions of various agonists on spike shape were investigated, individual spikes were evoked with 40 msec depolarizing pulses. In all experiments, the cells were superfused with a low- $\mathrm{Ca}^{2+}$, high- $\mathrm{Mg}^{2+} \mathrm{ASW}$ in order to depress excitability without affecting membrane potential (similar responses to the agonists were observed in control experiments using nASW). Cells were the same age as those used for the release experiments.

\section{Results}

Repeated stimulation of $B I$ and $B 2$ evokes reproducible release of labeled $S C P S$

Individual $\mathrm{B} 1$ and $\mathrm{B} 2$ cells, which had been previously labeled with ${ }^{35} \mathrm{~S}$-methionine, were stimulated via intracellular electrodes to fire three spikes in $0.5 \mathrm{sec}$ every other $0.5 \mathrm{sec}$ for $2 \mathrm{~min}$ in three sequential stimulation periods. Each stimulation period was bracketed with control periods during which the neurons were hyperpolarized. The collected superfusate from each period was run on HPLC, and the fractions corresponding to synthetic SCPs were counted. A typical experiment is illustrated in Figure $1 A$. The combined results from four such experiments indicated that the stimulation-dependent release of the SCPs exhibited only a small, steady decline over the three stimulation periods (Fig. $1 B$ ). These results suggested that the effects of putative modulators on the release of the SCPs could be examined by introducing the compound into the superfusate prior to the second stimulation period.

\section{Modulation of SCP release by FMRFamide, $S C P_{i}$, and 5-HT}

We tested whether FMRFamide, $\mathrm{SCP}_{\mathrm{A}}$, and 5-HT modulated release. A $1 \mu \mathrm{M}$ concentration of FMRFamide (Fig. 2A) substantially reduced the stimulation-dependent release of the SCPS $(t=9.0 ; P<0.01 ; n=3)$. This response was readily reversible.

Application of $1 \mu \mathrm{M} \mathrm{SCP}_{\mathrm{A}}$ (Fig. $2 B$ ) failed to produce any marked alteration in release of the radiolabeled SCPs $(t=1.41$, NS; $n=5$ ). It is possible that the slight increase in release observed in the second period was due to improved protection
A
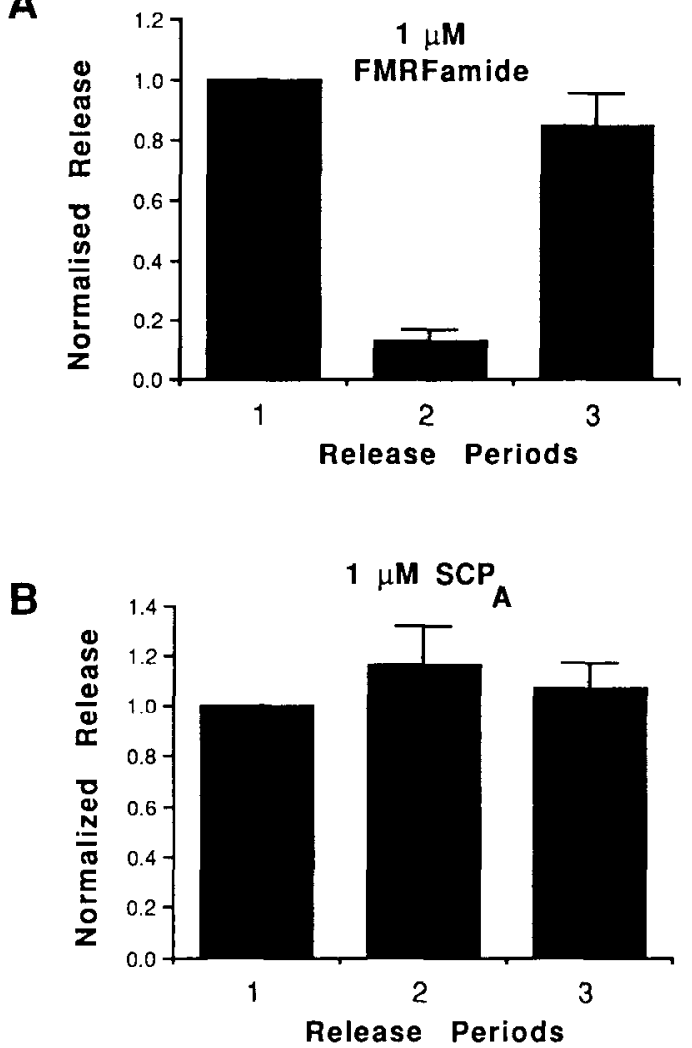

Figure 2. Action of FMRFamide and $\mathrm{SCP}_{\mathrm{A}}$ on the release of labeled SCPs. $A$, FMRFamide produces a transient decrease in release of the SCPs from B1 and B2. FMRFamide $(1 \mu \mathrm{M})$ was introduced into the superfusate for $10 \mathrm{~min}$ prior to the second stimulation period. Values are mean $\pm \operatorname{SEM}(n=3)$. Background release was $13 \pm 2 \%$ (mean \pm $\mathrm{SD}$ ) of the initial stimulus-evoked release. $B, \mathrm{SCP}_{\mathrm{A}}$ does not affect release of the SCPs from $\mathrm{B} 1$ and $\mathrm{B} 2 . \mathrm{SCP}_{\mathrm{A}}(1 \mu \mathrm{M})$ was introduced into the superfusate for $10 \mathrm{~min}$ prior to the second stimulation period. Values are mean $\pm \operatorname{SEM}(n=5)$. Background release was $16 \pm 8 \%($ mean \pm $\mathrm{SD})$ of the initial stimulus-evoked release.

of the radiolabeled peptides by the exogenous SCPs rather than by a direct effect on release.

Finally, 5-HT was found to depress the release of the SCPs from B1 and B2 (Fig. 3). Examination of the effect over a range of concentrations $(1-100 \mu \mathrm{M})$ indicated that the inhibitory action was dose dependent with an inhibition of $\sim 70 \%$ occurring at a concentration of $100 \mu \mathrm{M}$. Significant inhibition was observed at $10 \mu \mathrm{M}(t=2.37 ; P<0.05 ; n=3)$ and $100 \mu \mathrm{M}$ 5-HT $(t=7.73$; $P<0.01 ; n=6)$. The serotonergic inhibition of release was the same for both B1 and B2 at all concentrations tested (e.g., 100 $\mu \mathrm{M} ; t=0.08$, NS; $n=3$ ), in contrast to the actions of 5 -HT on cell excitability (see below). The inhibition was readily reversible.

\section{Elevation of CAMP levels depresses the release of the SCPS}

Since the actions of 5-HT in a variety of molluscan preparations are known to be associated with an increase in the intracellular levels of cAMP (Weiss et al., 1979; Shuster et al., 1985; Baxter and Byrne, 1989), we determined how a range of compounds known to raise cAMP levels affected the release of the SCPS.

In a series of experiments, FSK $(1 \mu \mathrm{M})$ was introduced into the superfusate for 30 min following the first stimulation period. This compound was found to produce a slow depression in the 
A

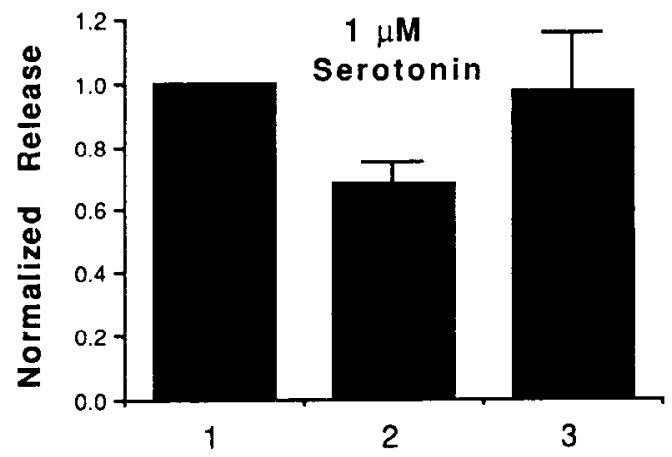

B

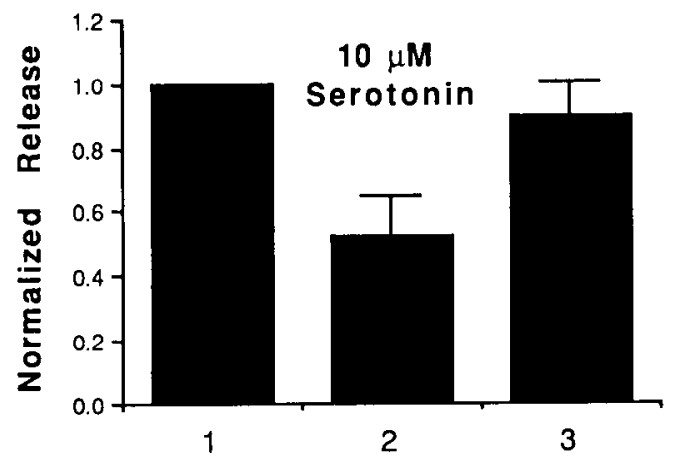

C

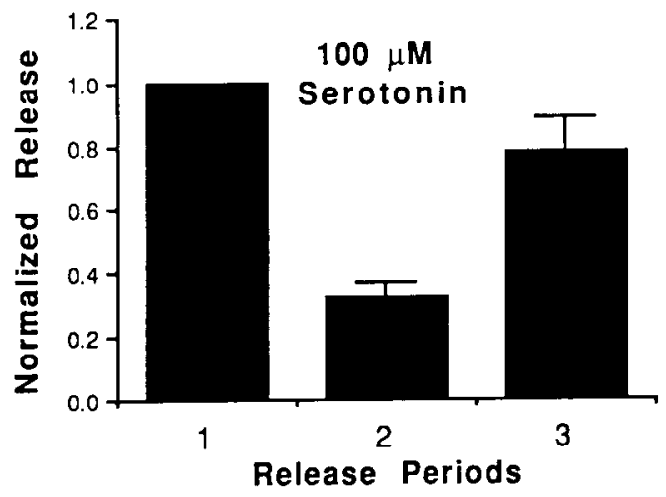

Figure 3. 5-HT produces a dose-dependent decrease in release of labeled SCPs from B1 and B2. 5-HT was introduced into the superfusate for $10 \mathrm{~min}$ prior to the second stimulation period at the indicated concentrations. Significant inhibition of peptide release was observed at $10 \mu \mathrm{M}$ and $100 \mu \mathrm{M} 5-\mathrm{HT}$. Values are mean \pm SEM $(n=3$, except $100 \mu \mathrm{M} 5$-HT, where $n=6$ ). Background release was $9 \pm 2 \%(A), 22$ $\pm 9 \%(B)$, and $16 \pm 8 \%(C)$ (mean \pm SD) of the initial stimulus-evoked release.

release of the SCPs (Fig. 4A). Significant inhibition was found only in the third stimulation period $(t=2.27 ; P<0.05 ; n=$ 3 ), consistent with the site of action being intracellular. However, FSK is known to have several actions on ion channels that are independent of adenylyl cyclase stimulation. Therefore, the effects of two chemically modified forms of FSK were also tested. Di FSK is an analog of FSK that does not activate adenylyl cyclase but reproduces many of the cAMP-independent effects of FSK (for review, see Laurenza et al., 1989). As shown in Figure $4 B$, this compound was without significant effect on the release of the SCPS $(t=0.25, \mathrm{NS} ; n=4$; third stimulation period), suggesting that the inhibition of release produced by FSK was likely to be duc to an clevation of cAMP levels. A secona mudified form of FSK, Mod FSK, has been recently used to mimic the cAMP-dependent actions of 5-HT on a variety of membrane currents in pleural sensory cells in Aplysia (Baxter and Byrne, 1991). Mod FSK can be used at higher concentrations than FSK while avoiding the cAMP-independent actions of FSK on membrane currents. Mod FSK $(50 \mu \mathrm{M})$ also inhibited release of radiolabeled SCPs (Fig. 4C). Furthermore, significant depression was found to occur in both the second and third stimulation periods $(t=2.11 ; P<0.05 ; n=3$; third stimulation period). This depression was quantitatively similar to that found with $1 \mu \mathrm{M}$ FSK and $10 \mu \mathrm{M}$ 5-HT.

Finally, we examined the effect of a $30 \mathrm{~min}$ application of an analog of cAMP, 8-(4-chlorophenylthio)cAMP (CPTcAMP; 1 $\mathrm{mM}$ ), upon release. A depression of release was observed in the second and third stimulation periods $(69 \pm 2 \%$ and $66 \pm 10 \%$, respectively, average percentage decrease $\pm \mathrm{SEM} ; n=2$ ).

Effect of FMRFamide, 5-HT, and $S C P_{A}$ on input resistance, excitability, spike shape, and membrane potential

One explanation for the ability of FMRFamide and 5-HT to depress the evoked release of the SCPs might be a hyperpolarization of membrane potential, which could lead to a reduction in spike duration and hence a reduction in transmitter release (although the membrane potential was held "constant" at the soma, fluctuations in the potential of the terminals might occur; see Discussion). We therefore examined the effect of the three agonists on several parameters that would be expected to reflect the overall level of cell excitability. Traditionally, B1 and B2 have been thought to be very similar neurons (but see Lloyd et al., 1985, 1988), and indeed both neurons had similar responses to FMRFamide and $\mathrm{SCP}_{\mathrm{A}}$. However, $5-\mathrm{HT}$ was found to affect the membrane potential of the two cells in culture differentially, and the actions of 5-HT on B1 and B2 were thus analyzed separately.

Input resistance. FMRFamide evoked a clear decrease in input resistance in both $\mathrm{B} 1$ and $\mathrm{B} 2(-20.6 \% ; t=3.05 ; P<0.05$; $n=4)$, while $\mathrm{SCP}_{\mathrm{A}}$ produced no change in this parameter in either cell $(4.5 \% ; t=1.24, \mathrm{NS} ; n=4)$. The effect of 5 -HT on $R_{\text {inpur }}$ was complex (Fig. 5A). 5-HT produced a dose-dependent increase in B1 cells that apparently saturated at $10 \mu \mathrm{M}$. In B2 cells, $1 \mu \mathrm{M}$ reduced the input resistance, with higher concentrations having no effect. This difference between B1 and B2 was not due to a difference in quality of impalement or general cell health since the control $R_{\text {input }}$ for the two similar-sized neurons was not significantly different $\left(R_{\text {input }}\right.$ for $\mathrm{B} 1$ was $15.2 \pm 0.3$, for B2 $13.2 \pm 1.8 \mathrm{M} \Omega ; t=1.08, \mathrm{NS} ; n=3$ ). The effects of all three agonists rapidly reversed upon washing. It should be noted that although FMRFamide and 5-HT affected $R_{\text {inpur }}$, the actions of these agonists may be complex. However, the elaborate neuritic fields that the cells generate in culture (Lloyd et al., 1986) preclude the generation of full $I-V$ curves.

Excitability. Cell excitability was monitored as the response of the cell to depolarizing current steps of $1.5 \mathrm{nA}$. The effects of FMRFamide and $\mathrm{SCP}_{\mathrm{A}}$ were straightforward. $\mathrm{SCP}_{\mathrm{A}}$ did not change the number of spikes evoked by depolarizing pulses on either B1 or B2 $(-4.6 \% ; t=1.65, \mathrm{NS} ; n=4)$, while FMRFamide produced a large decrease in excitability in both neurons $(-36.9 \% ; t=3.32 ; P<0.01 ; n=4)$. Both of these changes reflected the actions of the agonists on input resistance. Unlike FMRFamide and $\mathrm{SCP}_{\mathrm{A}}, 5-\mathrm{HT}$ had cell-specific effects on $R_{\text {inpu }}$ and spike number. On B1 cells, 5-HT increased $R_{\text {input }}$ and spike number (Fig. 5B). However, on B2 cells, 5-HT reduced or did 
A

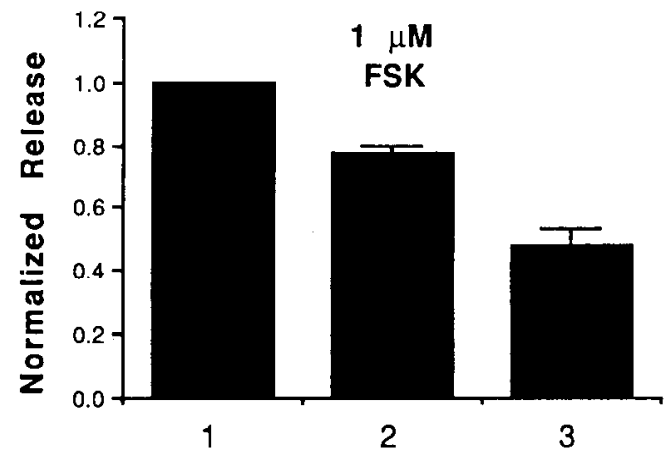

B

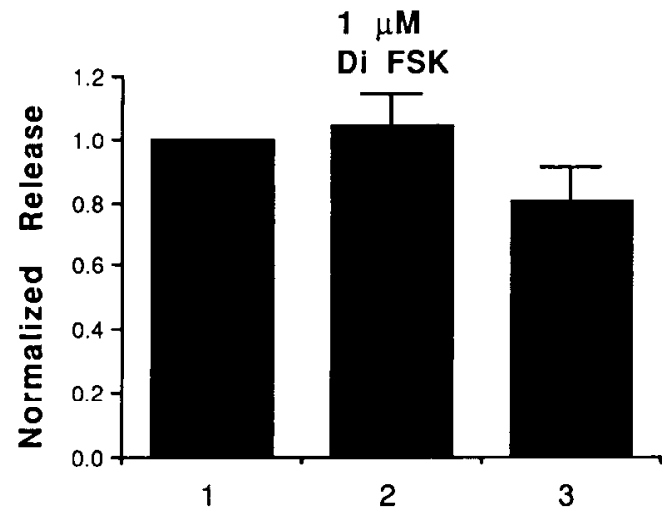

C

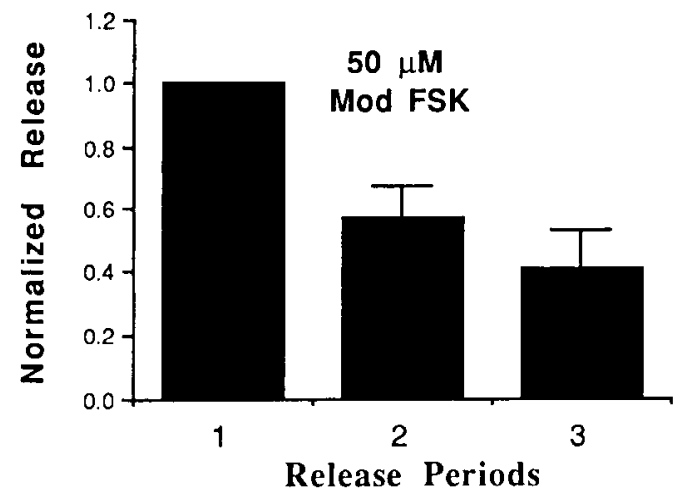

Figure 4. Effects of FSK and analogues on release of labeled SCPs from $\mathrm{B} 1$ and $\mathrm{B} 2$. A, FSK produces a long-lasting inhibition in release of the $\mathrm{SCPs}$ from B1 and B2. FSK $(1 \mu \mathrm{M})$ was introduced into the superfusate for 30 min prior to the second stimulation period. Values are mean \pm $\operatorname{SEM}(n=3)$. Background release was $6 \pm 2 \%$ (mean \pm SD) of the initial stimulus-evoked release. $B$, Di FSK, an analog of FSK that does not elevate cAMP levels (see Discussion), has no effect on the release of the SCPs from B1 and B2. Di FSK $(1 \mu \mathrm{M})$ was introduced into the superfusate for $30 \mathrm{~min}$ prior to the second stimulation period. Values are mean $\pm \operatorname{SEM}(n=5)$. Background release was $11 \pm 6 \%($ mean $\pm \operatorname{SD})$ of the initial stimulus-evoked release. $C$. Mod FSK produces a longlasting inhibition of release of the SCPs from B1 and B2. Mod FSK (50 $\mu \mathrm{M}$ ) was introduced into the superfusate for $30 \mathrm{~min}$ prior to the second stimulation period. Values are mean $\pm \operatorname{SEM}(n=3)$. Background release was $28 \pm 5 \%$ (mean \pm SD) of the initial stimulus-evoked release.

not effect $R_{\text {input }}$ and reduced the number of spikes evoked in response to the current pulse, particularly at low concentrations (1 $\mu \mathrm{M} ; t=2.22 ; P<0.05 ; n=3 ; 10 \mu \mathrm{M} ; t=5.8 ; P<0.01 ; n$ =3).

Spike shape. Only FMRFamide affected the amplitude of the evoked spikes $(-11.1 \% ; t=7.76 ; P<0.01 ; n=3)$. None of
A

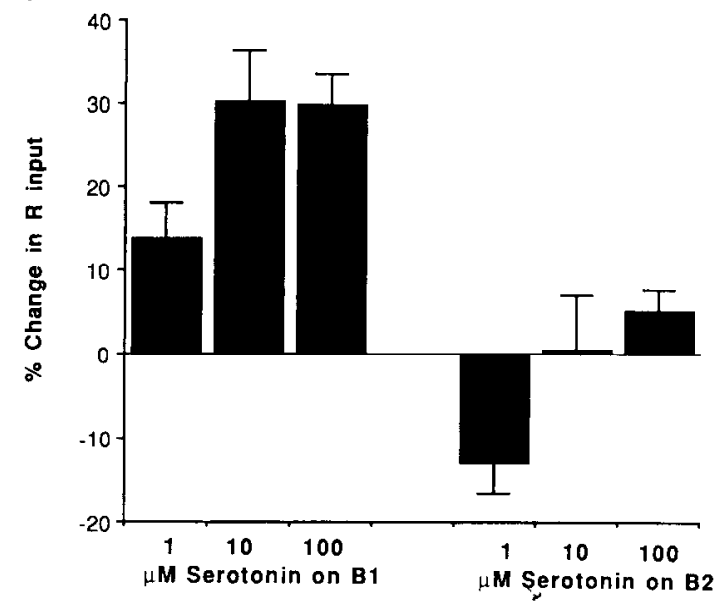

B

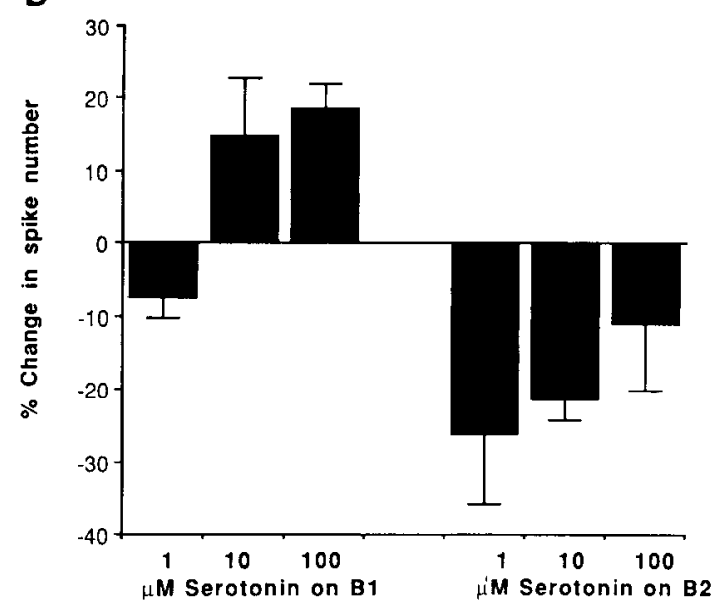

Figure 5. Effect of 5-HT on electrophysiological parameters designed to reflect the level of cell excitability. $A$, Effect on input resistance. $R_{\text {input }}$ was measured as the response of the cell to $0.5 \mathrm{nA}$ hyperpolarizing current pulses. Note that $1 \mu \mathrm{M} 5-\mathrm{HT}$ increases the input resistance of $\mathrm{B} 1$ but decreases the input resistance of $\mathrm{B} 2(n=3$ or 4$)$. $B$, Effect on number of spikes evoked by $1.5 \mathrm{nA}$ depolarizing current pulses. Same cells as in $A(n=3$ or 4$)$.

the compounds tested had a consistent effect on spike duration (measured at half-amplitude; data not shown).

Action of 5-HT on membrane potential in vitro and in situ. 5 -HT had differential effects on the membrane potential of B1 and B2. 5-HT depolarized B1 cells (12 of 13) and hyperpolarized $B 2$ cells (10 of 10). Typical examples of these responses are illustrated in Figure $6 \mathrm{~A}$. A $2 \mathrm{~min}$ application of $1 \mu \mathrm{M} 5$-HT depolarized B1 and hyperpolarized B2. These two cells were cultured from the same hemiganglion; thus, factors such as the length of time in culture could not explain the effects. We also examined the actions of 5-HT on B1 and B2 cells in the intact ganglion (Fig. 6B). As for the recordings from the cultured cells, the preparation was superfused with a low- $\mathrm{Ca}^{2+}$, high- $\mathrm{Mg}^{2+}$ ASW (which suppressed spontaneous synaptic activity) and 5-HT was injected as a bolus from a pipette positioned close to the somata of B1 and B2. 5-HT was found to depolarize both B1 and B2. When delivered as a $2 \mathrm{~min}$ application, 5-HT also depolarized B1 cells (six of six) and B2 cells (five of six; one cell did not respond). In contrast, all of the other compounds tested had similar actions on the two cells in vitro and in situ. 
A
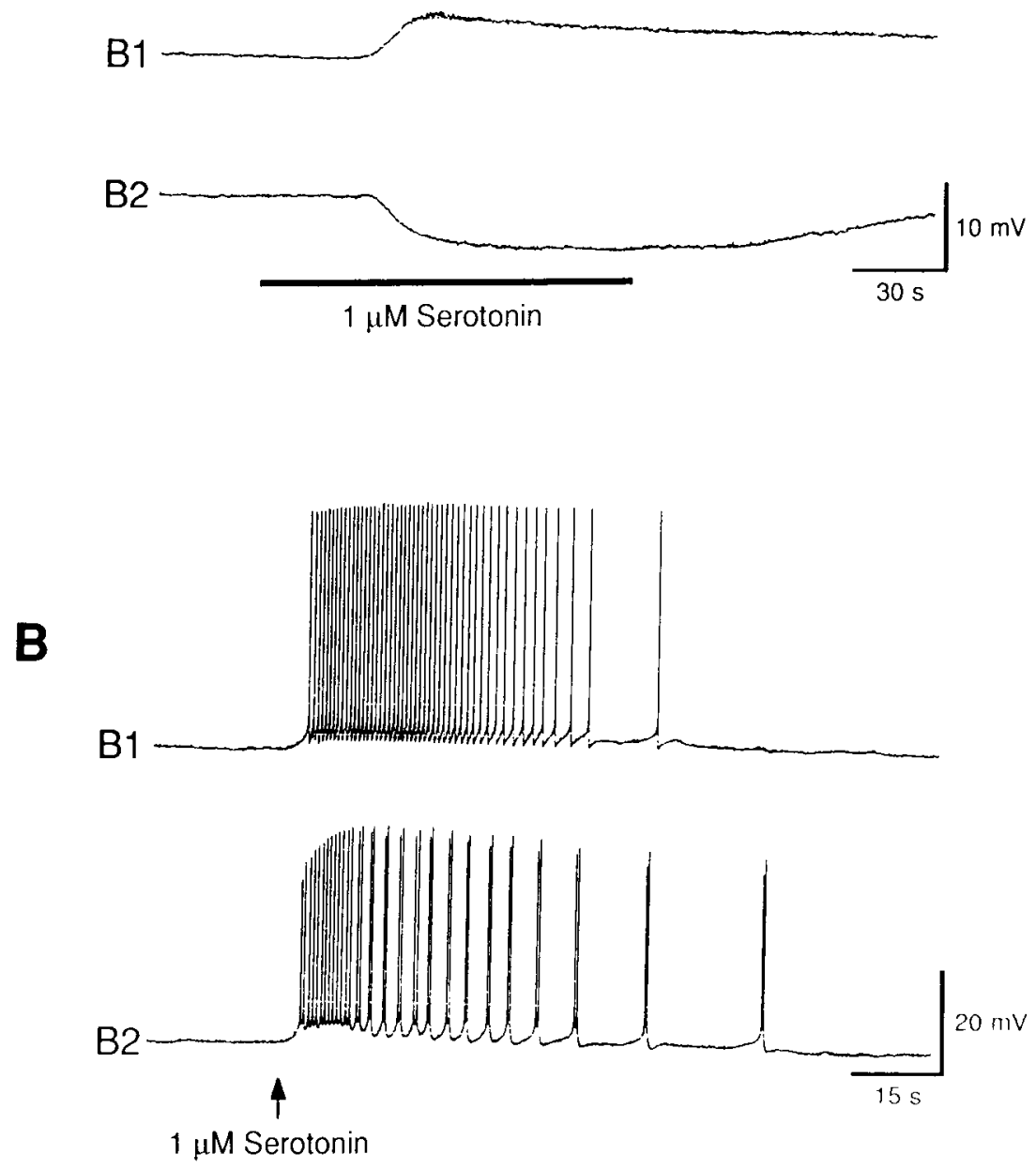

Figure 6. Action of 5-HT on $\mathrm{B} 1$ and $\mathrm{B} 2$ in vitro and in situ. $A, \mathrm{~A} 2$ min pulse of $1 \mu \mathrm{M} 5-\mathrm{HT}$ (bar) depolarizes B1 and hyperpolarizes B2 cells. Neurons were cultured from the same hemiganglion. Preparation was perfused with a low$\mathrm{Ca}^{3+}$, high- $\mathrm{Mg}^{\text {?+ }}$ ASW. Resting potential was $-40 \mathrm{mV}$. B, A $5 \mu \mathrm{l}$ bolus of 1 $\mu \mathrm{M}$ 5-HT (arrow) injected onto the somata of $\mathrm{B} 1$ and $\mathrm{B} 2$ depolarizes both cells to above spike threshold in situ. Cells were from the same hemiganglion. Preparation was perfused as in $A$. Resting potential was $-40 \mathrm{mV}$.

\section{Discussion}

The present results show that repeated stimulation of B1 or B2 cells in primary culture evokes a reproducible release of the SCPs into the bathing solution. Both neurons are known to contain large quantities of $\mathrm{SCP}_{\mathrm{A}}$ and $\mathrm{SCP}_{\mathrm{B}}$ (Lloyd et al., 1985), and this factor presumably contributed to our ability to evoke readily detectable release of these peptides using relatively brief stimulation paradigms. Since we do not know the size of the total pool of peptide in the cultured cells, it is possible that the labeled peptide that we recovered from the superfusate was drawn predominantly from the newly synthesized pool, as has been suggested to occur in the case of classical transmitters (Potter, 1970). Although we can make no quantitative assessment of this possibility, we can calculate that the total amount of labeled peptide released during a single expcriment is probably a few femtomoles, which is $<1 \%$ of the SCPs found in a cultured cell (Lloyd et al., 1986).

Recordings in the freely behaving animal indicate that $\mathrm{Bl}$ and B2 typically fire in association with swallowing movements for 1-2 sec at a frequency of up to 3 or $4 \mathrm{~Hz}$ (Lloyd et al., 1988). The stimulation parameters that we used to evoke peptide release from the cultured cells are thus similar to those observed in vivo. Although none of the compounds we tested produced a significant facilitation of peptide release, it is unlikely that this is due to the release already being maximal, since increasing the frequency of spikes produced an increase in the amount of labeled SCPs recovered from the superfusate (M. D. Whim, unpublished observations). Because the decline in peptide release over three stimulation periods was slight, we were able to examine the modulation of release by a variety of compounds. The results were somewhat unexpected since they did not always reflect the actions of the agonist on cell excitability. For example, 5-HT depolarized B1 but significantly inhibited the release of the SCPs. FMRFamide also inhibited release but hyperpolarized B1 and B2. There are several possible mechanisms that might explain the modulation of peptide release. For example, it is possible that the FMRFamide-evoked hyperpolarization of membrane potential $\left(V_{m}\right)$ lead to either spike failure or a decrease in spike duration. Both of these outcomes would produce a decrease in peptide release. However, several observations suggest that this is unlikely to explain our results. First, $V_{m}$ was held constant at the soma throughout the experiment. The length constant of the cultured cells is not known, and given the extensive fasiculation seen in similar preparations it would be difficult to estimate its value (see Schacher and Proshansky, 1983). Nevertheless, in vivo it may be several millimeters (Coates and Bulloch, 1985), which is an order of magnitude greater than the distance from the farthest varicosity to the cell body in these cultured cells. It is thus possible that we had reasonable control 
of $V_{m}$ at the presumed release sites even though we were recording in the cell body. Second, it is possible that release of the SCPs is insensitive to moderate changes in $V_{m}$ since 5-HT increased $R_{\text {input }}$ and depolarized B1 but inhibited peptide release. These changes in membrane properties are likely to increase the length constant and perhaps broaden the action potential and would thus be expected to increase rather than decrease release (Shapiro et al., 1980).

A second possible mechanism that could explain the observed inhibition of peptide release involves an FMRFamide- and 5-HT-evoked change in membrane currents, for example, a decrease in the calcium current in the terminals leading to a direct reduction of transmitter release (Brezina et al., 1987), or conversely, an increase in potassium currents leading indirectly to a decrease in release via a narrowing of the action potential (Klein and Kandel, 1980). More generally, changes in action potential shape have been suggested to underlie synaptic modulation in a wide variety of systems (Mudge et al., 1979; Klein and Kandel, 1980; Coates and Bulloch, 1985; McCobb and Beam, 1991), although it should be noted that alterations in action potential duration do not always lead to the expected change in transmitter release (Smith and Zucker, 1980; Hochner et al., 1986).

A third interpretation of the data concerns a more recently studied phenomenon. Several reports have suggested that FMR Famide and 5-HT can have a direct action on vesicular release (Man-Son-Hing et al., 1989; Dale and Kandel, 1990; Delaney et al., 1991). FMRFamide has been shown to inhibit spontaneous transmitter release at the synapses formed between cultured Aplysia neurons (Dale and Kandel, 1990). This action was independent of alterations in membrane currents and changes in the intracellular calcium concentration. Although the present report does not directly test this explanation, it is noteworthy that the effects of the agonists on cell excitability did not necessarily reflect their actions on neuropeptide release. Thus, 5-HT, which tended to increase the excitability of $\mathrm{B} 1$ and decrease the excitability of B2, inhibited the release of the SCPs from both cells to a similar degree. We therefore do not rule out the possibility that the actions of 5-HT or FMRFamide are mediated via a mechanism that is independent of altcrations in membrane conductance.

The role of CAMP in the modulation of peptide release is unclear. Both FSK and Mod FSK produced a marked depression of release. Di FSK, an analog of FSK that does not activate adenylyl cyclase, was without effect, suggesting that the actions of FSK involve a stimulation of adenylyl cyclase and subsequent elevation of CAMP levels. The ability of CPTCAMP to inhibit peptide release lends further support to the hypothesis that a rise in intracellular cAMP levels leads to a depression of peptide release. While the site of action of cAMP on $\mathrm{B} 1$ and $\mathrm{B} 2$ has not been identified, it is known that several proteins implicated in the transmitter release process are subject to phosphorylation by a variety of protein kinases (see Burgoyne, 1990). For example, synapsin I, a modulator of neurotransmitter release (Llinas et al., 1985; Lin et al., 1990), serves as a substrate for both cAMP- and calmodulin-dependent protein kinases (sce Dc Camilli and Greengard, 1986). However, direct evidence associating changes in the intracellular levels of cAMP with the actions of 5-HT or FMRFamide in the present system is difficult to obtain. Given the small volume of this region of the cell, it is not possible to measure changes in cAMP concentration in the terminals in response to agonist application. Furthermore,
cAMP is unlikely to be the sole mediator involved in the inhibitory actions of the agonists on release, particularly in light of the mechanisms elucidated in other preparations. A notable example of the complex way in which 5-HT affects transmitter release is provided by the action of 5-HT in facilitating synaptic transmission at identified sensory-motor neuron synapses in Aplysia. The facilitation seen in nondepressed synapses appears to be due largely to a broadening of the presynaptic spike (Klein and Kandel, 1980; Klein et al., 1982), while in the depressed synapse, 5-HT facilitates transmission via a mechanism that is largely independent of spike broadening (Hochner et al., 1986). A variety of second messenger systems are believed to be involved (Castellucci et al., 1980; Siegelbaum et al., 1982; Braha et al., 1990). Interestingly, 5-HT and cAMP thus appear to have the opposite action in the present system, where they were both found to depress transmitter release.

Finally, is it possible to draw any conclusions regarding the physiological roles played by $5-\mathrm{HT}, \mathrm{SCP}_{\mathrm{A}}$, and FMRFamide on peptide release? In a recent study, intracellular stimulation of $\mathrm{B} 1$ or B2 was shown to induce contractile activity in several regions of the gut. Further, the excitatory actions of B1 were indistinguishable from those produced by the application of the SCPs. In contrast, 5-HT inhibited contractile activity in the same region of the gut (Lloyd et al., 1988). We suggest that such data are consistent with the present results. Thus, in addition to inhibiting contractile activity directly, 5-HT will reduce the release of $\mathrm{SCP}_{\mathrm{A}}$ and $\mathrm{SCP}_{\mathrm{B}}$, two peptides whose function appears to be to increase gut activity. In addition, the evidence for a serotonergic input to $\mathrm{B} 1$ and $\mathrm{B} 2$ is clear. Stimulation of the serotonergic metacerebral cell produces a marked depolarization of both B1 and B2 (Gerschenfeld and Paupardin-Tritsch, 1974), an effect that is not eliminated in a high-divalent saline (M. D. Whim, unpublished observation), suggesting that at least a component of this connection is monosynaptic. Similarly, B 1 and $\mathrm{B} 2$ in the intact ganglion were found to depolarize in response to 5-HT. It thus appears that the serotonergic inhibition of SCP release could be of physiologic importance. There does, however, exist a discrepancy in the actions of 5-H' $\mathrm{T}$ on the cultured cells where the agonist depolarized B1 but hyperpolarized B2. The reason for this in situ/in vitro difference is unknown, but could arise as a result of the cell culture procedure or from a segregation of 5-HT receptor subtypes, with a dendritic receptor only being significantly exposed to applied 5-HT in the culture dish.

The inhibitory actions of FMRFamide are also likely to be of physiological importance. Authentic FMRFamide is present in the buccal ganglia of Aplysia (Lehman et al., 1984; Lloyd et al., 1987), and B1 and B2 are surrounded by FMRFamideimmunoreactive varicosities (Lloyd et al., 1987). However, the neurons that give rise to these varicosities have not been identified. $\mathrm{SCP}_{\mathrm{A}}$ did not significantly affect the release of the SCPS even though its application consistently resulted in a membrane depolarization, indicating that these neurons do express functional SCP receptors. However, these receptors do not significantly affect peptide release. Further, it is unlikely that the lack of an effect is duc to the relatively low concentration of $\mathrm{SCP}_{\mathrm{A}}$ used $(1 \mu \mathrm{M})$, since in other systems this dose evokes reponses comparable in magnitude to $10 \mu \mathrm{M}$ 5-HT (Abrams et al., 1984; Lloyd et al., 1984).

In conclusion, we have used a preparation consisting of cultured Aplysia cells to investigate the modulation of transmitter release. Both 5-HT and FMRFamide significantly, but tran- 
siently, inhibited release. The serotonergic inhibition of peptide release from Bl occurred even though this agonist increased cell excitability, indicating that this parameter does not provide an adequate predictor of transmitter release.

\section{References}

Abrams T, Castellucci VF, Camardo JS, Kandel ER, Lloyd PE (1984) Two endogenous neuropeptides modulate the gill and siphon withdrawal reflex in Aplysia by presynaptic facilitation involving cAMPdependent closure of a serotonin-sensitive potassium channel. Proc Natl Acad Sci USA 81:7956-7960.

Baxter DA, Byrne JH (1989) Serotonergic modulation of two potassium currents in the pleural sensory neurons of Aplysia. J Neurophysiol 62:665-679.

Baxter DA, Byrne JH (1991) Reduction of voltage-activated $\mathrm{K}^{+}$currents by forskolin is not mediated via cAMP in pleural sensory neurons of Aplysia. J Neurophysiol 64:1474-1483.

Belardetti F, Kandel ER, Siegelbaum SA (1987) Neuronal inhibition by the peptide FMRFamide involves opening of $S \mathrm{~K}^{\prime}$ channels. Nature 325:153-156.

Braha O, Dale N, Hochner B, Klein M, Abrams TW, Kandel ER (1990) Second messengers involved in the two processes of presynaptic facilitation that contribute to sensitization and dishabituation in Aplysia neurons. Proc Natl Acad Sci USA 87:2040-2044.

Brezina V, Eckert R, Erxleben C (1987) Suppression of calcium current by an endogenous neuropeptide in neurones of Aplysia californica. $\mathbf{J}$ Physiol (Lond) 388:565-595.

Burgoyne RD (1990) Secretory vesicle-associated proteins and their role in exocytosis. Annu Rev Physiol 52:647-659.

Castellucci VF, Kandel ER, Schwartz JH, Wilson FD, Nairn AC, Greengard P (1980) Intracellular injection of the catalytic subunit of cyclic AMP-dependent protein kinase simulates facilitation of transmitter release underlying behavioral sensitization in Aplysia. Proc Natl Acad Sci USA 77:7492-7496.

Cazalis M, Dayanthi G, Nordmann JJ (1985) The role of patterned burst and interburst interval on the excitation-coupling mechanism in the isolated rat neural lobe. J Physiol (Lond) 369:45-60.

Coates CJ, Bulloch AGM (1985) Synaptic plasticity in the molluscan peripheral nervous system: physiology and role for peptides. J Neurosci 5:2677-2684.

Cropper EC, Lloyd PE, Reed W, Tenenhaum R, Kupfermann I, Weiss KR (1987) Multiple neuropeptides in cholinergic motor neurons of Aplysia: evidence for modulation intrinsic to the motor circuit. Proc Natl Acad Sci USA 84:3486-3490.

Cropper EC, Price D, Tenenbaum R, Kupfermann I, Weiss KR (1990) Release of peptide cotransmitters from a cholinergic neuron under physiological conditions. Proc Natl Acad Sci USA 87:933-937.

Dale N, Kandel ER (1990) Facilitatory and inhibitory transmitters modulate spontaneous transmitter release at cultured Aplysia sensorimotor synapses. J Physiol (Lond) 421:203-222.

De Camilli, Greengard P (1986) Synapsin I: a synaptic vesicle-associated neuronal phosphoprotein. Biochem Pharmacol 35:4349-4357.

Delaney K, Tank DW, Zucker RS (1991) Presynaptic calcium and serotonin-mediated enhancement of transmitter release at crayfish neuromuscular junction. J Neurosci 1 1:2631-2643.

Dutton D, Dyball REJ (1979) Phasic firing enhances vasopressin release from the rat neurohypophysis. J Physiol (Lond) 290:433-440.

Gerschenfeld HM, Paupardin-Tritsch D (1974) On the transmittcr function of 5-hydroxytryptamine at excitatory and inhibitory monosynaptic junctions. J Physiol (Lond) 243:457-481.

Hall JD, Lloyd PE (1991) Release of pedal peptide from Aplysia neurons in primary culture. J Neurobiol 22:583-589.

Hochner B, Klein M, Schacher S, Kandel ER (1986) Additional component in the cellular mechanism of presynaptic facilitation contributes to behavioral dishabituation in Aplysia. Proc Natl Acad Sci USA 83:8794-8798.

Holz GG, Dunlap K, Kream RM (1988) Characterization of the electrically evoked release of substance $P$ from dorsal root ganglion neurons: methods and dihydropyridine sensitivity. J Neurosci 8:463471

Jan YN, Jan LY (1983) A LHRH-like peptidergic neurotransmitter capable of 'action at a distance' in autonomic ganglia. Trends Neurosci $6: 320-325$

Klein M, Kandel ER (1980) Mechanism of calcium current modula- tion underlying presynaptic facilitation and behavioral sensitization in Aplysia. Proc Natl Acad Sci USA 77:6912-6916.

Klein M, Camardo J, Kandel ER (1982) Serotonin modulates a specific potassium current in the sensory neurons that show presynaptic facilitation in Aplysia. Proc Natl Acad Sci USA 79:5713-5717.

Laurenza A, McHugh Sutkowski E, Seamon KB (1989) Forskolin: a specific stimulator of adenylyl cyclase or a diterpene with multiple sites of action? Trends Pharmacol Sci 10:442-447.

Lehman HK, Price DA, Greenberg MJ (1984) The FMRFamide-like neuropeptide of Aplysia is FMRFamide. Biol Bull 167:460-466.

Lin J, Sugimori M, Llinas RR, McGuinness TL, Greengard P (1990) Effects of synapsin I and calcium-dependent protein kinase II on spontaneous neurotransmitter release in the squid giant synapse. Proc Natl Acad Sci USA 87:8257-8261.

Llinas R, McGuinness TL, Leonard CS, Sugimori M, Greengard P (1985) Intraterminal injection of synapsin I or calcium/calmodulindependent protein kinasc II altcrs neurotransmitter release at the squid giant synapse. Proc Natl Acad Sci USA 82:3035-3039.

Lloyd PE, Kupfermann I, Weiss KR (1984) Evidence for parallel actions of a molluscan neuropeptide and serotonin in mediating arousal in Aplysia. Proc Natl Acad USA 81:2934-2937.

Lloyd PE, Mahon AC, Kupfermann I, Cohen JL, Scheller RH, Weiss KR (1985) Biochemical and immunocytological localization of molluscan small cardioactive peptides (SCPs) in the nervous system of Aplysia californica. J Neurosci 5:1851-1861.

Lloyd PE, Schacher S, Kupfermann I, Weiss KR (1986) Calciumdependent release of neuropeptides during intracellular stimulation of single identified Aplysia neurons in culture. Proc Natl Acad Sci USA 83:9794-9798.

Lloyd PE, Frankfurt M, Stevens P, Kupfermann I, Weiss KR (1987) Biochemical and immunocytological localization of the neuropeptides FMRFamide, $\mathrm{SCP}_{\mathrm{A}}$, and $\mathrm{SCP}_{\mathrm{B}}$, to neurons involved in the regulation of feeding in Aplysia. J Neurosci 7:1123-1132.

Lloyd PE, Kupfermann I, Weiss KR (1988) Central peptidergic neurons regulate gut motility in Aplysia. J Neurophysiol 59:1613-1626.

Lotshaw DP, Levitan I (1987) Serotonin and forskolin increase an inwardly rectifying potassium conductance in cultured identified Aplysia neurons. J Neurophysiol 58:909-921.

Mahon AC, Lloyd PE, Weiss KR, Kupfermann I, Scheller RH (1985) The small cardioactive peptides A and B of Aplysia are derived from a common precursor molecule. Proc Natl Acad Sci USA 82:39253929.

Man-Son-Hing H, Zoran MJ, Lukowiak K, Haydon PG (1989) A neuromodulator of synaptic transmission acts on the secretory apparatus as well as on ion channels. Nature 341:237-239.

McCobb DP, Beam KG (1991) Action potential waveform voltageclamp commands reveal striking differences in calcium entry via low and high voltage-activated calcium channels. Neuron 7:119-127.

Mudge A, Leeman SE, Fischbach GD (1979) Enkephalin inhibits release of substance $P$ from sensory neurons in culture and decreases action potential duration. Proc Natl Acad Sci USA 76:526-530.

Peng Y, Horn JP (1991) Continuous repetitive stimuli are more effective than bursts for evoking LHRH release in bullfrog sympathetic ganglia. J Neurosci 11:85-95.

Potter LT (1970) Synthesis, storage and release of $\left[{ }^{14} \mathrm{C}\right]$ acetylcholine in isolated rat diaphragm muscles. J Physiol (Lond) 206:145-166.

Rahamimoff R, Katz B (1986) Calcium, neuronal function and transmitter release. Boston: Martinus Nijhoff.

Schacher S, Proshansky E (1983) Neurite regeneration by Aplysia neurons in dissociated cell culture: modulation by Aplysia hemolymph and the presence of the initial axon segment. J Neurosci 3:2403-2413.

Shapiro E, Castellucci VF, Kandel ER (1980) Presynaptic membrane potential affects transmitter release in an identified neuron in Aplysia by modulating the $\mathrm{Ca}^{2+}$ and $\mathrm{K}^{+}$currents. Proc Natl Acad Sci USA 77:629-633.

Shuster MJ, Camardo JS, Siegelbaum SA, Kandel ER (1985) Cyclic AMP-dependent protein kinase closes the serotonin-sensitive $\mathrm{K}^{+}$ channels of Aplysia sensory neurones in cell-free membrane patches. Nature 313:392-395.

Siegelbaum SA, Camardo JS, Kandel ER (1982) Serotonin and cyclic AMP close single $\mathrm{K}^{+}$channels in Aplysia sensory neurones. Nature 299:413-417.

Smith SJ, Zucker RS (1980) Aequorin response facilitation and intracellular calcium accumulation in molluscan neurones. J Physiol (Lond) 300:167-196. 
Walker MW, Ewald DA, Perney TM, Miller RJ (1988) Neuropeptide $Y$ modulates neurotransmitter release and $\mathrm{Ca}^{2+}$ currents in rat sensory neurons. J Neurosci 8:2438-2446.

Weinreich D, McCaman MW, McCaman RE, Vaughn JE (1973) Chemical, enzymatic and ultrastructural characterization of 5-hydroxytryptamine-containing neurons from the ganglia of Aplysia californica and Tritonia diomedia. J Neurochem 20:969-976.

Weiss KR, Mandelbaum DE, Schonberg M, Kupfermann I (1979) Modulation of buccal muscle contractility by serotonergic metacerebral cells in Aplysia: evidence for a role of cyclic adenosine monophosphate. J Neurophysiol 42:791-803.
Whim MD, Lloyd PE (1989) Frequency-dependent release of peptide cotransmitters from identified cholinergic motor neurons in Aplysia. Proc Natl Acad Sci USA 86:9034-9038.

Whim MD, Lloyd PE (1990) Neuropeptide cotransmitters released from an identified cholinergic motor neuron modulate neuromuscular efficacy in Aplysia. J Neurosci 10:3313-3322.

Willard A (1990) A vasoactive intestinal peptide-like cotransmitter at cholinergic synapses between rat myenteric neurons in cell culture. $\mathbf{J}$ Neurosci 10:1025-1034. 